\title{
The Innate Immune Response to Infection by Polyascus gregaria in the Male Chinese Mitten Crab (Eriocheir sinensis), Revealed by Proteomic Analysis
}

\author{
Yanping Yang ${ }^{1,2}$, Fengjiao $\mathrm{Ma}^{3}$, Juanjuan Dong ${ }^{2}$, Lianxing $\mathrm{Li}^{2}{ }^{2}$, Ping Ren ${ }^{2}$, Yuning Zhang ${ }^{3}$, Yatao $\mathrm{Wu}^{1}$, \\ Yinping Wang ${ }^{2}$, Kai Liu ${ }^{2, *}$ and Fang Zhang ${ }^{1, *}$ \\ 1 College of Life Sciences, Anhui Normal University, Wuhu 241000, China; yangyp@ffrc.cn (Y.Y.); \\ wuyatao@ahnu.edu.cn (Y.W.) \\ 2 Scientific Observing and Experimental Station of Fishery Resources and Environment in the Lower Reaches \\ of the Changjiang River, Ministry of Agriculture and Rural Affairs, Freshwater Fisheries Research Center, \\ CAFS, Wuxi 214081, China; 18114862625@163.com (J.D.); lilianxing666@163.com (L.L.); \\ renping1234563@163.com (P.R.); wangyp@ffrc.cn (Y.W.) \\ 3 Wuxi Fishery College, Nanjing Agricultural University, Wuxi 214081, China; 15716176080@163.com (F.M.); \\ 2020213007@stu.njau.edu.cn (Y.Z.) \\ * Correspondence: liuk@ffrc.cn (K.L.); biozhf@ahnu.edu.cn (F.Z.)
}

Citation: Yang, Y.; Ma, F.; Dong, J.; Li, L.; Ren, P.; Zhang, Y.; Wu, Y.; Wang, Y.; Liu, K.; Zhang, F. The Innate Immune Response to Infection by Polyascus gregaria in the Male Chinese Mitten Crab (Eriocheir sinensis), Revealed by Proteomic Analysis. Fishes 2021, 6, 57. https://doi.org/10.3390/fishes6040057

Academic Editor: Lluís Tort

Received: 9 September 2021

Accepted: 29 October 2021

Published: 4 November 2021

Publisher's Note: MDPI stays neutral with regard to jurisdictional claims in published maps and institutional affiliations.

Copyright: (c) 2021 by the authors. Licensee MDPI, Basel, Switzerland. This article is an open access article distributed under the terms and conditions of the Creative Commons Attribution (CC BY) license (https:// creativecommons.org/licenses/by/ $4.0 /)$.

\begin{abstract}
The Chinese mitten crab (Eriocheir sinensis) is a representative catadromous invertebrate of the Yangtze River and a commercial species widely cultivated in China. Both cultivated and wild crabs suffer from a variety of parasites and pathogens, which can result in catastrophic economic losses in aquaculture revenue. Polyascus gregaria, a parasitic barnacle with a highly derived morphology, is specialized in invading these crabs. This study examines the immunological mechanism in E. sinensis infected with P. gregaria. Tandem mass tags (TMT), a specialized method of mass-spectrometry, was used to analyze the infection by $P$. gregaria resistance at the protein level. In the hepatopancreas of infected crabs, 598 proteins differentially expressed relating to physiological change, of which, 352 were upregulated and 246 were downregulated. Based on this differential protein expression, 104 GO terms and 13 KEGG pathways were significantly enriched. Differentially expressed proteins, such as ATG, cathepsin, serpin, iron-related protein, Rab family, integrin, and lectin, are associated with the lysosome GO term and the autophagy-animal KEGG pathways, both of which likely relate to the immune response to the parasitic $P$. gregaria infection. These results show the benefit of taking a detailed, protein-level approach to understanding the innate immune response of aquatic invertebrates to macroparasite infection.
\end{abstract}

Keywords: Eriocheir sinensis; Polyascus gregaria; TMT; innate immune; Yangtze Estuary

\section{Introduction}

The Chinese mitten crab (Eriocheir sinensis) is a well-known and important decapod crustacean with both ecological and economic value [1]. This migratory crustacean is native to the coastal waters of East Asia, but is now considered an invasive species throughout Europe and North America [2]. In China, more distinctive germplasm characteristics, and a high output of this native crustacean from the Yangtze River, are generally acknowledged by the public. Due to the commercial value of this species, intensive cultivation became popular after the 1950s [3] from the Yangtze River. Along with the rapid development of the large-scale aquaculture of these crabs are frequent outbreaks of viruses, bacteria, rickettsia-like organisms, and parasites, all of which have led to catastrophic economic losses for Chinese mitten crab farmers $[4,5]$. These infections can also cause remarkable morphological, physiological, and behavioral changes in the host [6]. Although the interactions among bacteria [7,8], funguses [9], parasites [10], and even ecological factors [6,11] in the host of the Chinese mitten crab, are represented in the literature, to date, there has 
been little focus on the parasitic barnacle Polyascus gregaria and its effect on the Chinese mitten crab. The hepatopancreas is an important organ in crustaceans that combines the various functions from the liver and pancreas in vertebrates [12]. It also relates the functioning of nutritional metabolism, energy storage, immune response, and other life activities in crustaceans [13-15]. For immune functioning, studies have demonstrated that the hepatopancreas synthesizes and excretes key immune-related molecules, such as beta-1, 3-glucan binding protein (LGBP) [16], antibacterial peptide (AMP) [17], and lectin related proteins [18], and emphasized the crucial roles in innate immune response in several crustaceans.

P. gregaria, as a member of the Rhizocephalan parasitic barnacle family, was originally classified as Sacculina polygenea [19], but was later reclassified in a new genus of Polyascus [20]. These parasites are regarded as the most specialized and divergent forms of barnacles, mainly infecting decapods, especially crab species, worldwide [21,22]. Key differences for rhizocephalans compared to other crustaceans include a high alteration of morphology, with a lack of segmentation and appendages in the adult stage. As with other barnacles, however, rhizocephalans show free-living nauplius and cypris larvae during reproduction, related to their endoparasitic lifestyles [23]. For example, Sacculinidae is one of the two larger families of Rhizocephalan, which causes host feminization [24], anecdysis, castration [18], gonadal atrophy [25], and immune response [26]. Moreover, the infection of this parasite in the Chinese mitten crab may result in the host death; the mortality of male crabs reached $13.04 \%$ and female crabs $9.09 \%$ in this research (total data not shown). For reproduction, the female host is forced to bear the parasitic barnacle eggs instead of its own, while in the male host, spermatogenesis is arrested and the gonadal tissue is degenerated, but does not disappear entirely [27]. Furthermore, changes in behavioral and external morphology, such as widening of the abdomen in parasitized males, cause the male host crabs to take on a feminine appearance [28]. For adult female barnacles, the body is made up of internal and external parts. The internal parts have hollow rootlets structures; these rootlets spread within the body of the host, including the ventral ganglionic mass, gonad, muscle, hemolymph, and hepatopancreas [27,29], where they absorb nutrients from the host [23]. The external portion of the barnacle plays a temporarily reproductive role and is critically responsible for infection in the host. The external parts generate nauplius larvae, which develop into a cypris larvae after several molts to start a new round infection.

Recently, several studies were published on Sacculinidae ecology [30,31], the histopathology and immune response in Carcinus maenas [22], the effects on the muscular system in Hemigrapsus sanguineus [5], and the molecular mechanisms of infection in Scylla olivacea [32]. Studies have specifically addressed the disease ecology of $P$. gregaria [33], its phylogenetic relationships [19], as well as the description of its morphological adaptation to parasitism in Hemigrapsus sanguineus [34]. As an economical crustacean, the diseases and immunity of the Chinese mitten crab are particularly important to aquaculturists. Due to the lack of an acquired immune system, the innate immune system is the first line of inducible host defense in invertebrates against bacterial, fungal, and viral pathogens [35]. This defense system includes phagocytosis, melanization, nodulation, encapsulation, and the release of relative bactericidal substances, and is essential for the survival and perpetuation of all multicellular organisms [36]. In this area, many studies have demonstrated the functional genes, crucial proteins, osmoregulation modes, antioxidant capacity, and innate immune pathways involved in various diseases in the Chinese mitten crab $[14,15,37]$. In addition, studies examining the protein levels of the innate immune response could provide important insights into this field of research. One such method is the use of isobaric tandem mass tag (TMT) mass-spectrometry. This technology has allowed researchers to illustrate the molecular mechanisms of inflammatory responses, infections, and temperature responses $[11,38,39]$.

In this study, we examined the innate immune response of the male Chinese mitten crab to $P$. gregaria infection through TMT analysis. This proteomic analysis provides a deep insight into the relationship and interaction between the Chinese mitten crab and 
P. gregaria. We identified hundreds of new relevant proteins and assessed their biological importance through enrichments of gene ontology (GO) terms and Kyoto Encyclopedia of Genes and Genomes (KEGG) pathways to discriminate the immunological mechanisms involved in the response to $P$. gregaria infection. These results provide a novel, deep, and comprehensive view of the innate immune response in the Chinese mitten crab, especially for macroparasites, which provide an academic reference for preventing the infection by P. gregaria, to reduce the economic losses in agricultural farm. These molecular mechanisms also contribute toward pharmacological research and development, regarding new medicine against parasite infection.

\section{Materials and Methods}

\subsection{Sample Site and Crabs}

Male Chinese mitten crabs were obtained from the Yangtze Estuary $\left(31^{\circ} 10^{\prime} 59.06^{\prime \prime} \mathrm{N}-\right.$ $121^{\circ} 53^{\prime} 40.56^{\prime \prime}$ E), Shanghai, China, in December 2020, during the spawning migration. Animals were collected from gill nets ( $5 \mathrm{~mm}$ mesh), set perpendicular to the water flow after 2-3 h in the water. Crabs were quickly stunned on ice as soon as they were caught and immediately taken to the lab. The biological information of each crab was measured and the abdomen was scrutinized to separate animals parasitized with $P$. gregaria from those without the parasites. Slight exfoliation was necessary to collect the parasites and to note the number. Next, 4-5 g of hepatopancreas tissue was rapidly extracted from both parasitized and non-parasitized crabs, and they were flash frozen in liquid nitrogen. All of the extracted samples were stored at $-80^{\circ} \mathrm{C}$ to ensure effectiveness of the tissue. The parasites collected from each host were identified based on their morphological characteristics [40]. Crabs were considered healthy (i.e., non-parasitized) if no parasite or scar was found in the abdomen, appendages, or copulatory organ, while those with at least 15 parasites evident in the abdomen were considered of the parasitized crabs (Figure 1). Six non-parasitized (mean \pm SD, case length: $56.67 \pm 0.98 \mathrm{~mm}$ ) and six parasitized (mean $\pm \mathrm{SD}$, case length: $53.19 \pm 7.02 \mathrm{~mm}$; parasite count: $21 \pm 4$ ) (Table 1) were chosen to analyze the innate immune response in this present study.

Table 1. The basic information of Chinese mitten crab samples.

\begin{tabular}{ccccccc}
\hline Groups & Sample ID & CL $(\mathbf{m m})$ & $\mathbf{C W}(\mathbf{m m})$ & $\mathbf{C T}(\mathbf{m m})$ & Weight $(\mathbf{g})$ & PN \\
\hline \multirow{5}{*}{ non-parasitized } & ESC1 & 54.92 & 51.57 & 26.43 & 76.06 & 0 \\
& ESC2 & 57.22 & 53.34 & 26.08 & 85.34 & 0 \\
& ESC3 & 56.19 & 56.19 & 29.34 & 80.12 & 0 \\
& ESC4 & 56.87 & 51.51 & 37.97 & 89.42 & 0 \\
& ESC5 & 57.57 & 55.45 & 31.76 & 98.87 & 0 \\
& ESC6 & 57.24 & 56.32 & 27.76 & 105.42 & 0 \\
\hline \multirow{5}{*}{ Parasitized } & ESI1 & 61.63 & 58.25 & 28.84 & 102.19 & 21 \\
& ESI2 & 49.83 & 48.06 & 23.41 & 60.00 & 17 \\
& ESI3 & 54.30 & 53.49 & 26.58 & 80.94 & 27 \\
& ESI4 & 46.52 & 47.07 & 22.20 & 46.96 & 21 \\
& ESI5 & 45.74 & 43.73 & 20.94 & 46.46 & 17 \\
& ESI6 & 61.11 & 59.53 & 28.02 & 106.66 & 24 \\
\hline
\end{tabular}

CL: case length; CW: case width; CT: case thickness; PN: parasite number. 


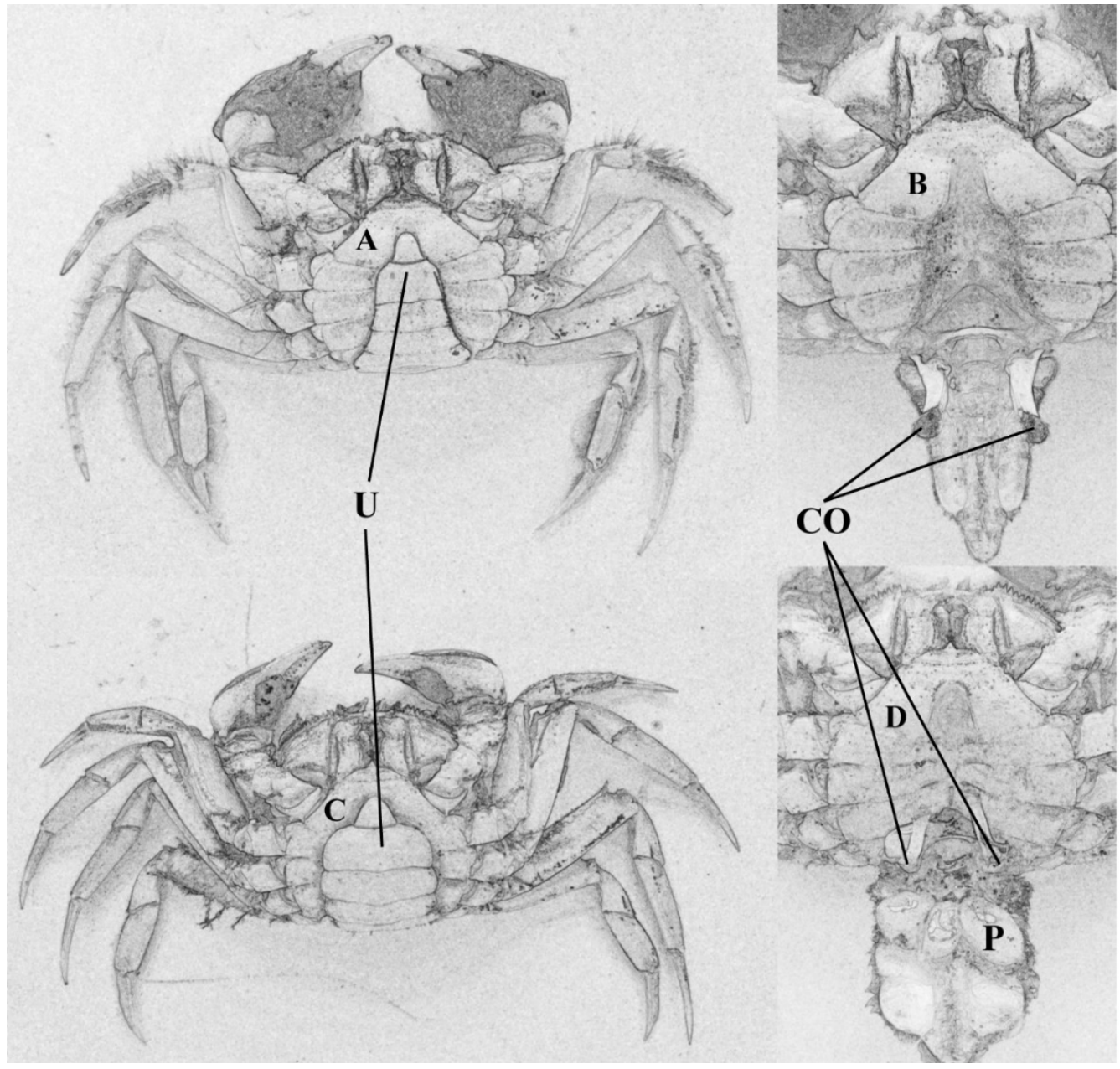

Figure 1. Features in the male Chinese mitten crab infected with P. gregaria. (A,B): non-parasitized crab; (C,D): parasitized crab. U: umbilicus; CO: copulatory organ; P: P. gregaria.

\subsection{Experimental Protein Preparation}

A single-to differential (STD) buffer was added to hepatopancreas tissue and then transferred into $2 \mathrm{~mL}$ tubes with quartz sand (1:1). An MP Fastprep-24 Automated Homogenizer was used to homogenize the lysate in 2 cycles, $6.0 \mathrm{M} / \mathrm{S}$ for $30 \mathrm{~s}$. The homogenate was sonicated and then boiled for $15 \mathrm{~min}$, followed by centrifugation at 14,000 $\mathrm{g}$ for $40 \mathrm{~min}$. The supernatant was filtered through a $0.22 \mu \mathrm{m}$ filter and quantified with the BCA Protein Assay Kit (P0012, Beyotime) before being stored at $-20^{\circ} \mathrm{C}$. To separate proteins, a $20 \mu \mathrm{g}$ of $6 \mathrm{X}$ loading buffer was mixed in each sample and boiled for $5 \mathrm{~min}$. The concentrations of proteins were detected (Table S1) and the proteins were separated on 12.5\% SDS-PAGE gel (Figure S1) and visualized by Coomassie Blue R-250 staining.

A total of $200 \mu \mathrm{g}$ of proteins was taken for each sample and combined with $30 \mu \mathrm{L}$ of STD buffer (4\% sodium dodecyl sulfate (SDS), $100 \mathrm{mM}$ dithiothreitol (DTT), and $150 \mathrm{mM}$ Tris- $\mathrm{HCl} \mathrm{pH} \mathrm{8.0).} \mathrm{The} \mathrm{detergent,} \mathrm{DTT,} \mathrm{and} \mathrm{other} \mathrm{low-molecular-weight} \mathrm{components} \mathrm{were}$ removed using UA buffer ( $8 \mathrm{M}$ Urea, $150 \mathrm{mM}$ Tris- $\mathrm{HCl} \mathrm{pH} \mathrm{8.5)} \mathrm{by} \mathrm{repeated} \mathrm{ultrafiltration}$ (Sartorius (Göttingen, Germany) $30 \mathrm{kD}$ ). Then, $100 \mu \mathrm{L}$ of iodoacetamide (100 mM IAA in UA buffer) was added to block reduced cysteine residues and the samples were incubated for $30 \mathrm{~min}$ in darkness. The filters were washed three times with $100 \mu \mathrm{L}$ of UA buffer and then twice with $100 \mu \mathrm{L}$ of $0.1 \mathrm{M}$ triethylammonium bicarbonate (TEAB) buffer. Finally, the protein suspensions were digested with $4 \mu \mathrm{g}$ of trypsin (Promega, Madison, WI, USA) in $40 \mu \mathrm{L} 0.1 \mathrm{M} \mathrm{TEAB}$ buffer overnight at $37^{\circ} \mathrm{C}$. The resulting peptides were collected as a filtrate. The peptide content (Figure S2) was estimated by UV light spectral density at 
$280 \mathrm{~nm}$ that was calculated based on the frequency of tryptophan and tyrosine in vertebrate proteins.

\subsection{TMT Protein Labelling and HPLC Fractionation}

The $100 \mu \mathrm{g}$ peptide mixture of each sample was labeled using TMT reagent, according to the manufacturer's instructions (Thermo Fisher Scientific, Waltham, MA, USA). Each TMT labeled mixture was then fractionated by RP chromatography using the Agilent 1260 infinity II HPLC. Next, the mixture was diluted with buffer A (10 mM HCOONH4, $5 \%$ ACN, pH 10.0) and loaded onto an XBridge Peptide BEH C18 Column, $130 \AA, 5 \mu \mathrm{m}$, $4.6 \mathrm{~mm} \times 100 \mathrm{~mm}$ column. The peptides were eluted at a flow rate of $1 \mathrm{~mL} / \mathrm{min}$ with a gradient of $0-7 \%$ buffer B (10 mM HCOONH4, 85\% ACN, pH 10.0) for $5 \mathrm{~min}, 7-40 \%$ buffer B for 5-40 min, $40-100 \%$ buffer B for $45-50 \mathrm{~min}$, and $100 \%$ buffer B for $50-65 \mathrm{~min}$. The elution was monitored at $214 \mathrm{~nm}$ based on the UV light trace, and fractions were collected every $1 \mathrm{~min}$ between 5 and $50 \mathrm{~min}$.

\subsection{LC-MS/MS Analysis}

Each fraction was injected for nanoLC-MS/MS analysis. The peptide mixture was loaded onto the C18-reversed phase analytical column (Thermo Fisher Scientific, Acclaim PepMap RSLC 50 um $\times 15 \mathrm{~cm}$, nano viper, P/N164943) in buffer A (0.1\% Formic acid), and separated with a linear gradient of buffer B ( $80 \%$ acetonitrile and $0.1 \%$ Formic acid) at a flow rate of $300 \mathrm{nl} / \mathrm{min}$. The gradient consisted of $6 \%$ buffer B for $3 \mathrm{~min}, 6-28 \%$ buffer B for $42 \mathrm{~min}, 28-38 \%$ buffer B for $5 \mathrm{~min}, 38-100 \%$ buffer B for $5 \mathrm{~min}$, and $100 \%$ buffer B for $5 \mathrm{~min}$. The peptides were analyzed by a Q Exactive Plus mass spectrometer (Thermo Fisher Scientific) that was coupled to Easy nLC (Thermo Fisher Scientific) for $90 \mathrm{~min}$. The mass spectrometer was operated in positive ion mode. MS data were acquired using a data-dependent top 10 method, dynamically choosing the most abundant precursor ions from the survey scan (350-1800 $\mathrm{m} / \mathrm{z}$ ) for high-energy collisional dissociation (HCD) fragmentation. Survey scans were acquired at a resolution of 70,000 at $\mathrm{m} / \mathrm{z} 200$ with an automatic generation control (AGC) target of $3 \mathrm{e} 6$ and a maxIT of $50 \mathrm{~ms}$. MS2 scans were acquired at a resolution of 17,500 for HCD spectra at $m / z 200$ with an AGC target of $2 \times 10^{5}$ and a maxIT of $45 \mathrm{~ms}$, and isolation width was $2 \mathrm{~m} / \mathrm{z}$. Only ions with a charge state between 2 and 6, and a minimum intensity of $2 \times 10^{3}$ were selected for fragmentation. Dynamic exclusion for selected ions was $30 \mathrm{~s}$. Normalized collision energy was $30 \mathrm{eV}$.

\subsection{Data Analysis}

MS/MS raw files were processed using MASCOT engine (Matrix Science, London, UK; version 2.6), analyzed in Proteome Discoverer 2.2 (Thermo Fisher Scientific), and searched against the UniProt database. The search parameters included trypsin as the enzyme used to generate peptides with a maximum of 2 missed cleavages permitted. A precursor mass tolerance of $10 \mathrm{ppm}$ was specified and 0.05 Da tolerance for MS2 fragments. Except for TMT labels, carbamidomethyl(C) was set as a fixed modification. Variable modifications were oxidation (M) and acetyl (protein N-term). A peptide and protein false discovery rate (FDR) of $1 \%$ was enforced using a reverse database search strategy. Proteins with fold change $>1.2$ and $p$-value (Student's $t$ test) $<0.05$ were considered to be differentially expressed proteins.

\subsection{Enrichment of Pathways Analysis}

All protein sequences were aligned to protein database that were assembled (Trinity, V2.4.0) and predicted (TransDecoder, V3.0.1) from the coding sequence of transcriptome, only the sequences in the top 10 and E-value $\leq 0.001$ were kept. The GO term of the sequence with the top bit-score by Blast2GO was selected. Then, the annotations from GO terms to proteins was completed by the Blast2GO Command Line. After the basic annotation, InterProScan/GO (http:/ / www.ebi.ac.uk/interpro/ (accessed on 5 October 2021)) was used to search the EBI database by motif and then add the functional information 
of the motif to proteins to improve annotation. Fisher's exact test was used to enrich GO terms and KEGG pathways by comparing the number of differentially expressed proteins and total proteins correlated to GO terms. Correction for multiple hypothesis testing was carried out using standard false discovery rate (FDR) control methods.

\subsection{Enrichment of Protein Domain Analysis}

InterProScan (http:/ / www.ebi.ac.uk/interpro (accessed on 1 November 2021)) was used to predict the protein families, domains, and special sites based on the protein sequence alignment method. The database was blasted and the two-tailed Fisher's exact test was employed, aiming to test the enrichment of the differentially expressed proteins against all identified proteins. A correction for multiple hypothesis testing was performed using the FDR, and the $p$-values $<0.05$ were considered as a significant domain.

\section{Results}

\subsection{Identification and Quantitative Protein Profiling}

The parasites were identified in six Chinese mitten crabs based on morphological characters, such as size, profile, parasitic location, color, and capture site in this study. The proteomic analysis was successfully performed on hepatopancreas tissue from six parasitized and six non-parasitized male crabs based on the TMT method, along with simultaneous identification and quantification. In total, 10,616 unique peptides and 2143 proteins were identified, of which 2046 proteins showed quantitative information. Using a 1.2-fold increase or decrease as a benchmark, 598 proteins showed differential expression between parasitized and non-parasitized crabs. Of these, 352 were upregulated and 246 were downregulated in response to $P$. gregaria infection. Among the upregulated proteins, several kinds of proteins related to the innate immune system were identified, such as cathepsin $\mathrm{F}$ and GTPase KRas, while immune system related proteins in the downregulated set included: serpin B, Autophagy-related 4 (ATG4), ATG5, ATG9, scavenger receptor class B, cathepsin D and L, and lectin (Table 2).

Table 2. Representative differentially expressed proteins related to the innate immune system in the Chinese mitten crab, with a 1.2-fold change, with P. gregaria infection.

\begin{tabular}{|c|c|c|c|c|}
\hline Protein ID & Name & Coverage & 1.2-Fold & $p$ Value \\
\hline Unigene003240.p1 & Cell division control protein 42 & 17 & 2.63 & 0.0000 \\
\hline Unigene000553.p1 & E3 ubiquitin-protein ligase HERC4 & 4 & 1.96 & 0.0000 \\
\hline Unigene003237.p1 & Ras-related protein Rab-7A & 26 & 1.30 & 0.0001 \\
\hline Unigene005035.p1 & UTP-glucose-1-phosphate uridylyltransferase & 22 & 1.30 & 0.0002 \\
\hline Unigene000566.p1 & Ras-related GTP-binding protein A/B & 17 & 1.34 & 0.0005 \\
\hline Unigene004773.p1 & Chaperonin GroEL & 38 & 1.73 & 0.0007 \\
\hline Unigene002294.p1 & Ras-related protein Rab-30 & 17 & 2.04 & 0.0010 \\
\hline Unigene000261.p1 & Dynactin 1 & 2 & 1.71 & 0.0032 \\
\hline Unigene003260.p1 & Ras-related protein Rab-6A & 39 & 2.02 & 0.0033 \\
\hline Unigene004729.p1 & High mobility group protein B1 & 7 & 1.41 & 0.0034 \\
\hline Unigene002219.p1 & Ras homolog gene family, member A & 29 & 1.56 & 0.0039 \\
\hline Unigene004782.p1 & Calreticulin & 33 & 2.81 & 0.0041 \\
\hline Unigene006723.p1 & Ras-related protein Rab-1A & 43 & 1.85 & 0.0044 \\
\hline Unigene000585.p1 & Cathepsin F & 4 & 1.40 & 0.0045 \\
\hline Unigene000091.p1 & Kindlin 2 & 8 & 1.39 & 0.0055 \\
\hline Unigene007453.p1 & Small subunit ribosomal protein s6e & 28 & 2.07 & 0.0059 \\
\hline Unigene000740.p1 & Ras-related protein Rab-2A & 50 & 1.69 & 0.0073 \\
\hline Unigene004596.p1 & Protein disulfide-isomerase A1 & 49 & 1.71 & 0.0115 \\
\hline Unigene004078.p2 & Tubulin-specific chaperone A & 16 & 2.51 & 0.0124 \\
\hline Unigene001138.p1 & Matrix metalloproteinase-14 & 3 & 1.44 & 0.0150 \\
\hline Unigene000336.p1 & GTPase KRas & 12 & 2.06 & 0.0167 \\
\hline Unigene007460.p1 & Small subunit ribosomal protein s3e & 53 & 1.38 & 0.0250 \\
\hline Unigene000055.p1 & Laminin, alpha $3 / 5$ & 16 & 1.26 & 0.0270 \\
\hline Unigene006004.p1 & Vacuolar protein-sorting-associated protein 4 & 8 & 1.37 & 0.0294 \\
\hline
\end{tabular}


Table 2. Cont.

\begin{tabular}{|c|c|c|c|c|}
\hline Protein ID & Name & Coverage & 1.2-Fold & $p$ Value \\
\hline Unigene005905.p1 & $\begin{array}{c}\text { Complement component } 1 \text { Q subcomponent-binding } \\
\text { protein, mitochondrial }\end{array}$ & 15 & 2.33 & 0.0297 \\
\hline Unigene003829.p1 & Protein scribble & 13 & 1.31 & 0.0304 \\
\hline Unigene001410.p1 & Fascin 1 & 4 & 1.83 & 0.0342 \\
\hline Unigene006225.p1 & Glutathione S-transferase & 36 & 2.06 & 0.0006 \\
\hline Unigene000029.p1 & P-type Ca2+ transporter type $2 \mathrm{~B}$ & 9 & 1.48 & 0.0178 \\
\hline Unigene000668.p1 & Filamin & 7 & 1.36 & 0.0038 \\
\hline Unigene001686.p1 & 1,4-alpha-glucan branching enzyme & 27 & 1.35 & 0.0004 \\
\hline Unigene001793.p1 & Neural cell adhesion molecule & 4 & 2.30 & 0.0408 \\
\hline Unigene005645.p1 & AN1-type zinc finger protein 1 & 4 & 4.77 & 0.0005 \\
\hline Unigene003973.p1 & KRAB domain-containing zinc finger protein & 2 & 4.82 & 0.0082 \\
\hline Unigene000005.p1 & Integrin alpha 7 & 8 & 0.72 & 0.0003 \\
\hline Unigene000042.p1 & Lysosomal alpha-glucosidase & 9 & 0.32 & 0.0021 \\
\hline Unigene000381.p1 & Integrin beta 1 & 11 & 0.51 & 0.0069 \\
\hline Unigene000396.p1 & Cysteine protease ATG4 & 7 & 0.78 & 0.0108 \\
\hline Unigene000417.p1 & Serpin B & 67 & 0.49 & 0.0147 \\
\hline Unigene000427.p1 & Glycerol-3-phosphate O-acyltransferase 1/2 & 4 & 0.60 & 0.0044 \\
\hline Unigene000486.p1 & Hexosaminidase & 34 & 0.49 & 0.0211 \\
\hline Unigene000506.p1 & Vacuolar protein sorting-associated protein 35 & 21 & 0.79 & 0.0108 \\
\hline Unigene000515.p1 & Lectin, mannose-binding 2 & 13 & 0.73 & 0.0267 \\
\hline Unigene000557.p1 & CD63 antigen & 11 & 0.53 & 0.0214 \\
\hline Unigene000614.p1 & Dipeptidyl-peptidase 4 & 18 & 0.50 & 0.0150 \\
\hline Unigene000677.p1 & Integrin alpha 8 & 17 & 0.71 & 0.0099 \\
\hline Unigene000679.p1 & Protein kinase D & 6 & 0.66 & 0.0186 \\
\hline Unigene000969.p1 & Spondin-1 & 2 & 0.70 & 0.0418 \\
\hline Unigene001066.p1 & Guanine nucleotide exchange factor VAV & 4 & 0.71 & 0.0200 \\
\hline Unigene001121.p1 & Ubiquitin-associated and SH3 domain-containing protein & 5 & 0.55 & 0.0354 \\
\hline Unigene001159.p1 & Protein spaetzle & 10 & 0.55 & 0.0003 \\
\hline Unigene001277.p1 & Beta-mannosidase & 11 & 0.55 & 0.0295 \\
\hline Unigene001291.p1 & Vacuolar protein sorting-associated protein 18 & 2 & 0.63 & 0.0310 \\
\hline Unigene001385.p1 & Beta-mannosidase & 12 & 0.58 & 0.0441 \\
\hline Unigene001395.p1 & Serine/threonine-protein phosphatase 4 catalytic subunit & 5 & 0.55 & 0.0015 \\
\hline Unigene001452.p1 & Neurobeachin & 9 & 0.73 & 0.0024 \\
\hline Unigene001494.p1 & Integrin beta 1 & 3 & 0.47 & 0.0449 \\
\hline Unigene001509.p1 & Serine incorporator $1 / 3$ & 1 & 0.48 & 0.0116 \\
\hline Unigene001818.p1 & Presenilin 1 & 2 & 0.65 & 0.0055 \\
\hline Unigene001922.p1 & Autophagy-related protein 9 & 2 & 0.66 & 0.0129 \\
\hline Unigene002296.p1 & Glutamyl aminopeptidase & 18 & 0.74 & 0.0103 \\
\hline Unigene003160.p1 & Cathepsin D & 26 & 0.68 & 0.0046 \\
\hline Unigene003249.p1 & Scavenger receptor class $\mathrm{B}$, member 1 & 11 & 0.57 & 0.0020 \\
\hline Unigene003625.p1 & Importin subunit alpha- $6 / 7$ & 7 & 0.78 & 0.0287 \\
\hline Unigene004822.p1 & Ras-related protein Rab-27A & 6 & 0.63 & 0.0277 \\
\hline Unigene004984.p1 & Lysosomal-associated membrane protein $1 / 2$ & 10 & 0.60 & 0.0080 \\
\hline Unigene005731.p1 & Glyceraldehyde 3-phosphate dehydrogenase & 77 & 0.51 & 0.0329 \\
\hline Unigene005921.p1 & Autophagy-related protein 5 & 7 & 0.54 & 0.0144 \\
\hline Unigene006505.p1 & Cathepsin L & 23 & 0.65 & 0.0149 \\
\hline Unigene002835.p1 & Actin related protein $2 / 3$ complex, subunit 5 & 31 & 0.64 & 0.0135 \\
\hline Unigene005574.p1 & Ferritin heavy chain & 59 & 0.53 & 0.0196 \\
\hline Unigene000294.p1 & Titin & 13 & 0.77 & 0.0067 \\
\hline Unigene006063.p1 & Niemann-Pick C2 protein & 34 & 0.53 & 0.0168 \\
\hline Unigene003415.p1 & Beta-glucuronidase & 24 & 0.39 & 0.0020 \\
\hline Unigene001334.p1 & Mannose-6-phosphate isomerase & 17 & 0.78 & 0.0336 \\
\hline Unigene006110.p1 & Mannose receptor, $C$ type & 5 & 0.63 & 0.0190 \\
\hline Unigene006396.p1 & Cystatin-A/B & 23 & 0.52 & 0.0050 \\
\hline Unigene000181.p1 & Vacuole morphology and inheritance protein 14 & 5 & 0.60 & 0.0084 \\
\hline Unigene000974.p1 & Abhydrolase domain-containing protein 5 & 9 & 0.66 & 0.0317 \\
\hline Unigene000708.p1 & AP- 1 complex subunit beta- 1 & 15 & 1.64 & 0.0001 \\
\hline
\end{tabular}




\subsection{GO Enrichment}

The analysis of GO terms that were significantly enriched in differentially expressed proteins showed a total of $104 \mathrm{GO}$ terms (Table S2). Cellular component terms were especially enriched for the lysosomal lumen, plasma membrane, smooth endoplasmic reticulum, and azurophil granule membrane. Molecular function GO terms were enriched for carbohydrate binding, guanosine triphosphate (GTP) binding, GTPase activity, and others. Biological process terms were mainly enriched for antigen processing and presentation, hemocyte migration, nuclear-transcribed mRNA catabolic process, nonsense-mediated decay, and regulation of filopodium assembly (Figure 2). Of the enriched GO terms, 31 were related to immune response, including autophagosome assembly, immune effector process, astrocyte activation involved in immune response, innate immune response, and adaptive immune response (Table 3).

Table 3. Enrichment of GO terms related to innate immune response in the Chinese mitten crab infected with $P$. gregaria.

\begin{tabular}{|c|c|c|c|c|}
\hline GO-ID & GO-Term & Category & $p$-Value & Diff \\
\hline GO:0043202 & Lysosomal lumen & $\mathrm{C}$ & 0.00 & 10 \\
\hline GO:0008305 & Integrin complex & $\mathrm{C}$ & 0.00 & 10 \\
\hline GO:0005764 & Lysosome & $\mathrm{C}$ & 0.01 & 19 \\
\hline GO:0045298 & Tubulin complex & $\mathrm{C}$ & 0.01 & 7 \\
\hline GO:0000421 & Autophagosome membrane & $\mathrm{C}$ & 0.14 & 3 \\
\hline GO:0001772 & Immunological synapse & $\mathrm{C}$ & 1.00 & 1 \\
\hline GO:0019882 & Antigen processing and presentation & $\mathrm{P}$ & 0.00 & 5 \\
\hline GO:0035099 & Hemocyte migration & $\mathrm{P}$ & 0.00 & 6 \\
\hline GO:0000045 & Autophagosome assembly & $\mathrm{P}$ & 0.01 & 6 \\
\hline GO:0032482 & Rab protein signal transduction & $\mathrm{P}$ & 0.01 & 7 \\
\hline GO:0002252 & Immune effector process & $\mathrm{P}$ & 0.08 & 2 \\
\hline GO:0030683 & Evasion or tolerance by virus of host immune response & $\mathrm{P}$ & 0.08 & 2 \\
\hline GO:0002322 & B cell proliferation involved in immune response & $\mathrm{P}$ & 0.28 & 1 \\
\hline GO:0002309 & $\mathrm{T}$ cell proliferation involved in immune response & $\mathrm{P}$ & 0.28 & 1 \\
\hline GO:0002265 & Astrocyte activation involved in immune response & $\mathrm{P}$ & 0.28 & 1 \\
\hline GO:0002842 & $\begin{array}{c}\begin{array}{c}\text { Positive regulation of } \mathrm{T} \text { cell mediated immune response to } \\
\text { tumor cell }\end{array}\end{array}$ & $\mathrm{P}$ & 0.28 & 1 \\
\hline GO:0002739 & Regulation of cytokine secretion involved in immune response & $\mathrm{P}$ & 0.28 & 1 \\
\hline GO:0061844 & $\begin{array}{c}\text { Antimicrobial humoral immune response mediated by } \\
\text { antimicrobial peptide }\end{array}$ & $\mathrm{P}$ & 0.28 & 1 \\
\hline GO:0002684 & Positive regulation of immune system process & $\mathrm{P}$ & 0.31 & 2 \\
\hline GO:0045087 & Innate immune response & $\mathrm{P}$ & 0.37 & 5 \\
\hline GO:0002682 & Regulation of immune system process & $\mathrm{P}$ & 0.41 & 3 \\
\hline GO:0002840 & Regulation of T cell mediated immune response to tumor cell & $\mathrm{P}$ & 0.48 & 1 \\
\hline GO:0002429 & $\begin{array}{l}\text { Immune response-activating cell surface receptor signaling } \\
\text { pathway }\end{array}$ & $\mathrm{P}$ & 0.48 & 1 \\
\hline GO:0002286 & $\mathrm{T}$ cell activation involved in immune response & $\mathrm{P}$ & 0.48 & 1 \\
\hline GO:0006955 & Immune response & $\mathrm{P}$ & 0.62 & 2 \\
\hline GO:0002376 & Immune system process & $\mathrm{P}$ & 0.75 & 4 \\
\hline GO:0002250 & Adaptive immune response & $\mathrm{P}$ & 1.00 & 1 \\
\hline
\end{tabular}

P: biology process; C: cellular component; Diff: the number of different expression proteins corresponding to the term. 


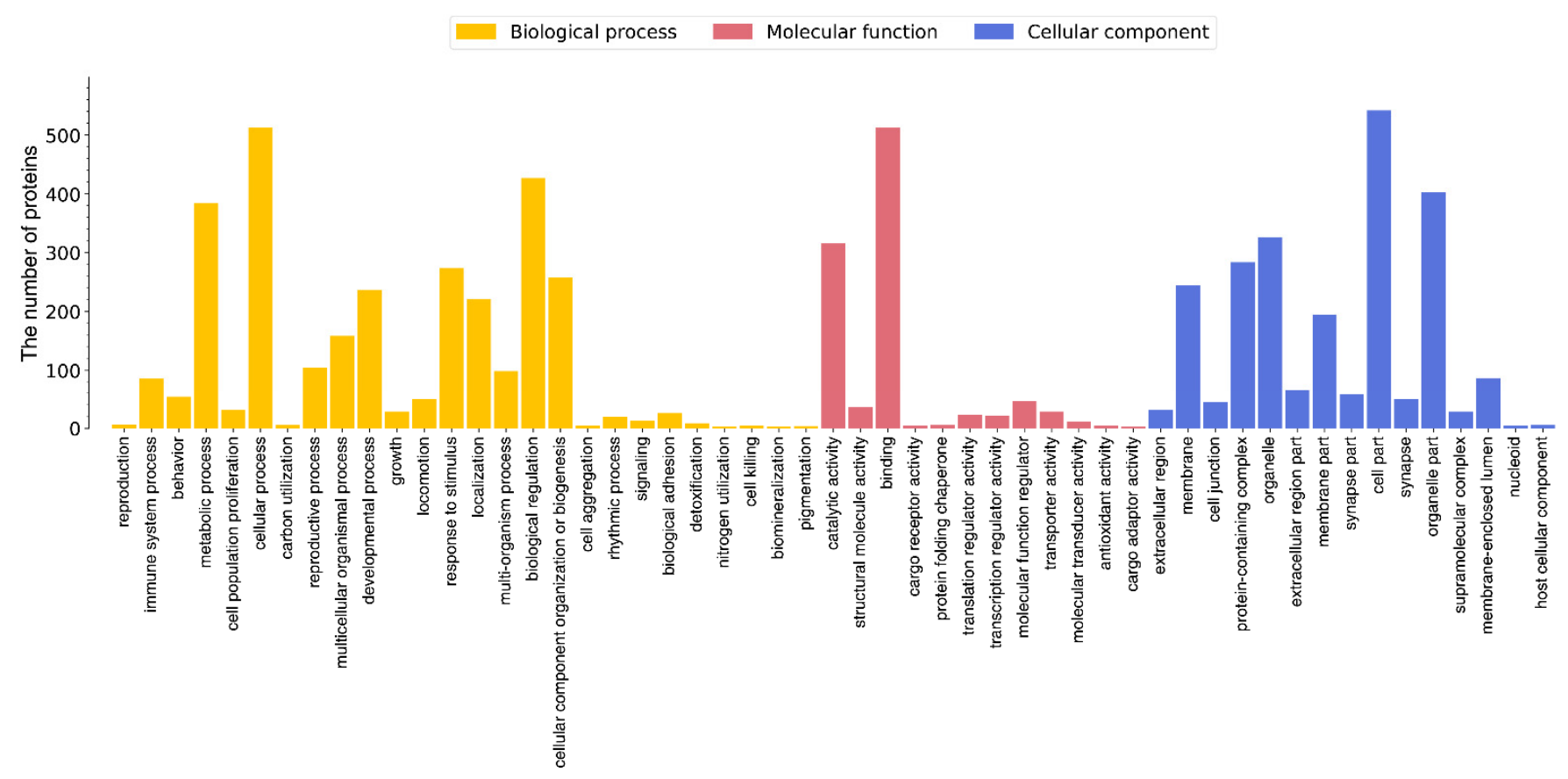

Figure 2. Enrichment of GO terms for DEPs in the Chinese mitten crab infected with P. gregaria.

\subsection{KEGG Analysis with DEPs}

In the KEGG pathway analysis, a total of 13 pathways were significantly $(p<0.05)$ enriched in the set of differentially expressed proteins (Figure 3, Table 4). These pathways included lysosome, protein processing in endoplasmic reticulum, extracellular matrix (ECM)_receptor interaction, other glycan degradation, proteoglycans in cancer, glycosaminoglycan degradation, focal adhesion, antigen processing and presentation, autophagy animal, endocytosis, nucleotide excision repair, and ribosome.

\section{KEGG Enrichment Scatter Plot}

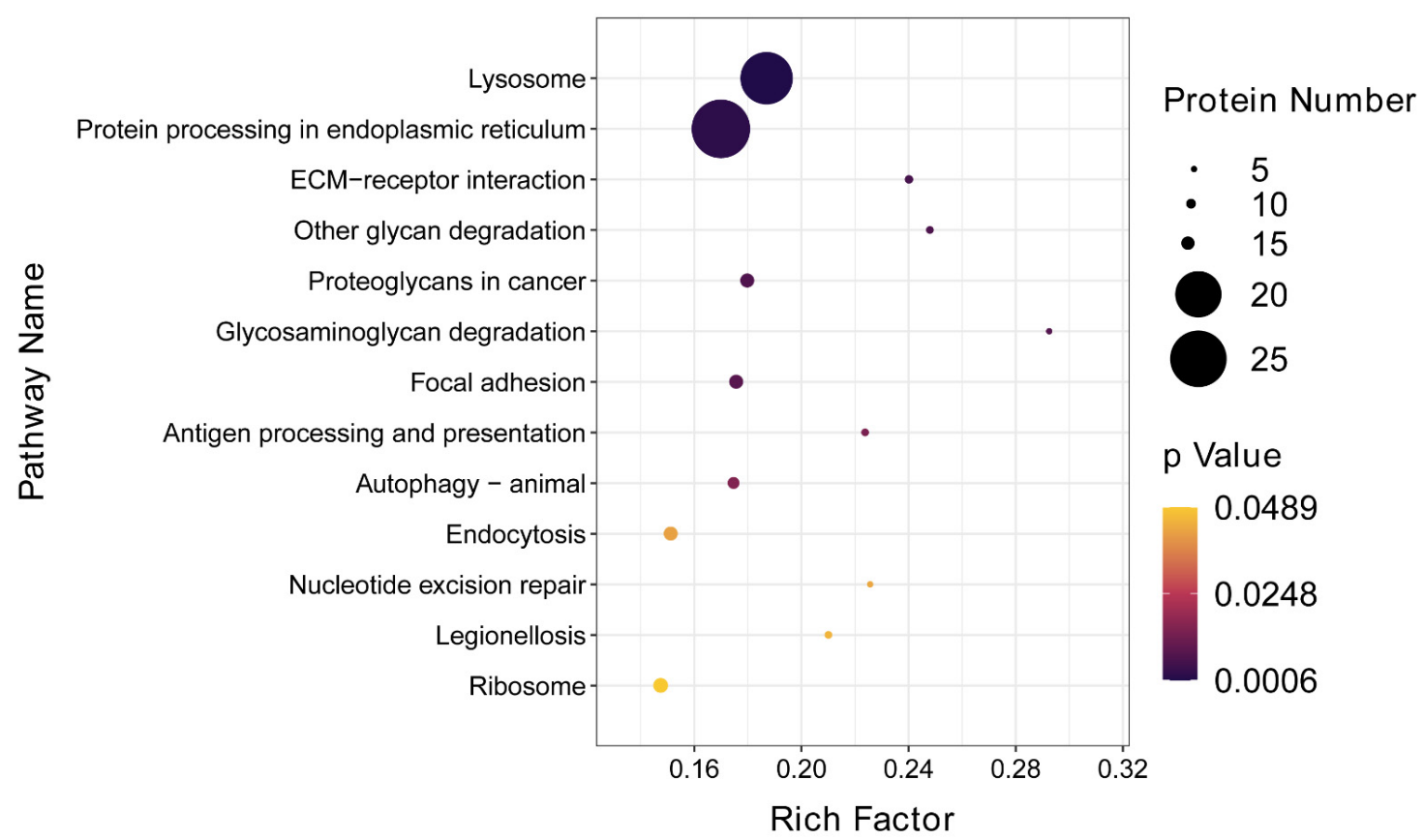

Figure 3. Significant enrichment of KEGG pathways $(p<0.05)$ for DEPs in the Chinese mitten crab infected with $P$. gregaria. 
Table 4. Significant enrichment of KEGG pathways $(p<0.05)$ in the Chinese mitten crab infected with $P$. gregaria.

\begin{tabular}{lccc}
\hline Map ID & Map Name & $p$-Value & Diff \\
\hline k004142 & Lysosome & 0.00 & 23 \\
k004141 & Protein processing in endoplasmic reticulum & 0.00 & 26 \\
k004512 & ECM-receptor interaction & 0.01 & 8 \\
k00511 & Other glycan degradation & 0.01 & 7 \\
k005205 & Proteoglycans in cancer & 0.01 & 16 \\
k00531 & Glycosaminoglycan degradation & 0.01 & 5 \\
k004510 & Focal adhesion & 0.01 & 7 \\
k004612 & Antigen processing and presentation & 0.01 & 13 \\
k004140 & Autophagy animal & 0.02 & 16 \\
k004144 & Endocytosis & 0.04 & 5 \\
k003420 & Nucleotide excision repair & 0.04 & 7 \\
k005134 & Legionellosis & 0.05 & 17 \\
\hline
\end{tabular}

Diff: the number of different expression proteins corresponding to the pathway.

\subsection{Enrichment of Protein Domain}

Proteins were clustered (Figure S3) and the protein domains were further analyzed for enrichment in order to better understanding the functional aspects of the DEPs. We found significant enrichment of 32 domain categories (Table 5), including the small GTPbinding protein domain, glycoside hydrolase superfamily, glycosyl hydrolase, ferritin-like, and ferritin.

Table 5. Significant enrichment of protein domains $(p<0.05)$ in the Chinese mitten crab infected with P. gregaria.

\begin{tabular}{|c|c|c|c|c|}
\hline ID & Source & Domain & $p$-Value & Diff \\
\hline IPR005225 & InterPro & Small GTP-binding protein domain & 0.00 & 17 \\
\hline IPR017853 & InterPro & Glycoside hydrolase superfamily & 0.00 & 14 \\
\hline IPR013780 & InterPro & Glycosyl hydrolase, all-beta & 0.00 & 8 \\
\hline IPR012675 & InterPro & Beta-grasp domain superfamily & 0.00 & 5 \\
\hline PR00449 & PRINTS & Transforming protein P21 Ras signature & 0.00 & 11 \\
\hline IPR002939 & InterPro & Chaperone DnaJ, C-terminal & 0.01 & 4 \\
\hline IPR008971 & InterPro & HSP40/DnaJ peptide-binding & 0.01 & 4 \\
\hline cd10747 & CDD & DnaJ_C & 0.01 & 4 \\
\hline IPR012676 & InterPro & TGS-like & 0.01 & 4 \\
\hline PS51419 & ProSiteProfiles & Small GTPase Rab1 family profile. & 0.01 & 7 \\
\hline IPR020568 & InterPro & Ribosomal protein S5 domain 2-type fold & 0.01 & 8 \\
\hline IPR013320 & InterPro & Concanavalin A-like lectin/glucanase domain superfamily & 0.01 & 8 \\
\hline IPR032695 & InterPro & Integrin domain superfamily & 0.02 & 5 \\
\hline IPR029044 & InterPro & Nucleotide-diphospho-sugar transferases & 0.02 & 5 \\
\hline IPR001806 & InterPro & Small GTPase superfamily & 0.02 & 10 \\
\hline IPR018526 & InterPro & Glycoside hydrolase, family 29 , conserved site & 0.02 & 3 \\
\hline IPR012347 & InterPro & Ferritin-like & 0.02 & 3 \\
\hline cd14752 & CDD & GH31_N & 0.02 & 3 \\
\hline IPR031919 & InterPro & Alpha-L-fucosidase, C-terminal & 0.02 & 3 \\
\hline IPR009078 & InterPro & Ferritin-like superfamily & 0.02 & 3 \\
\hline IPR036156 & InterPro & Beta-Galactosidase/glucuronidase domain superfamily & 0.02 & 3 \\
\hline IPR000933 & InterPro & Glycoside hydrolase, family 29 & 0.02 & 3 \\
\hline IPR016286 & InterPro & Alpha-L-fucosidase, metazoa-type & 0.02 & 3 \\
\hline IPR004095 & InterPro & TGS & 0.02 & 3 \\
\hline IPR001519 & InterPro & Ferritin & 0.02 & 3 \\
\hline IPR000980 & InterPro & SH2 domain & 0.02 & 4 \\
\hline IPR036860 & InterPro & SH2 domain superfamily & 0.02 & 4 \\
\hline IPR015940 & InterPro & Ubiquitin-associated domain & 0.02 & 4 \\
\hline IPR029048 & InterPro & Heat shock protein 70 kD, C-terminal domain superfamily & 0.02 & 4 \\
\hline IPR006689 & InterPro & Small GTPase superfamily, ARF/SAR type & 0.02 & 4 \\
\hline IPR001841 & InterPro & Zinc finger, RING-type & 0.04 & 1 \\
\hline IPR009060 & InterPro & UBA-like superfamily & 0.04 & 5 \\
\hline
\end{tabular}




\subsection{Subcellular Location of DEPS}

Obtaining information about the subcellular location is an important and helpful step towards understanding the mechanism and function of proteins. In the present study, location in the cytosol was enriched with $33.9 \%$ of DEPs $(n=203)$ located there. The second most enriched subcellular location was the mitochondria ( $\mathrm{n}=110,18.4 \%$ of all DEPs). The least enriched location was the peroxisome, with two DEPs (Figure 4).

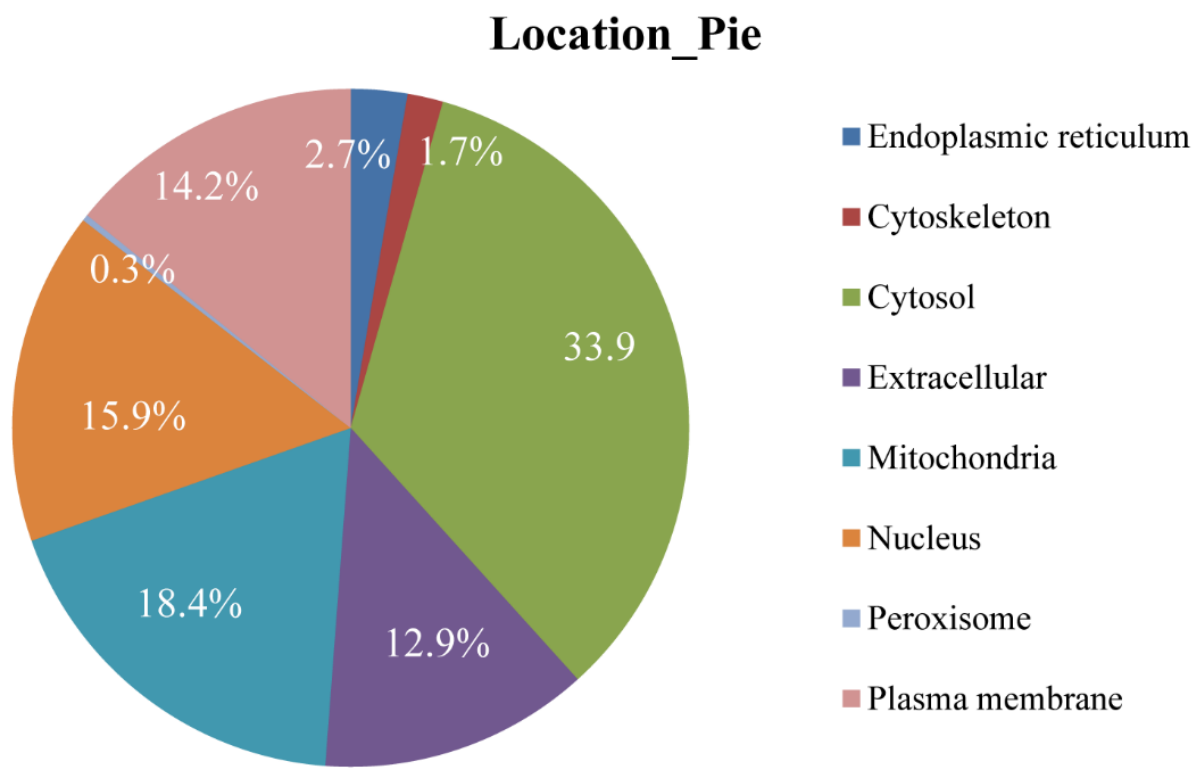

Figure 4. The subcellular location of DEPs identified in the Chinese mitten crab infected with P. gregaria.

\section{Discussion}

The Chinese mitten crab, as an economically important crab, has become increasingly popular in the freshwater aquaculture industry; it is now widely cultured in the provinces of Jiangsu, Anhui, Hubei, and Liaoning in China [41]. Several types of hepatopancreatic diseases from bacteria, viruses, and parasites were reported on in recent years, but little attention has been devoted to the innate immune response to macroparasites in this crab species. Here, we focus on the importance of enriched GO terms, the KEGG pathway, and functional protein domains to reveal substantial insights into the innate immune response of this host-parasite system. Importantly, we found that these components, including GTPase KRas, complement 1q-binding protein (C1QBP), serpin, ATG5, lysosomal lumen term, autophagosome assembly terms, antigen processing, the presentation pathway, and the autophagy animal pathway.

Autophagy is an intracellular degradation system that plays an important role in maintaining cellular homeostasis, and is evolutionarily conserved from yeast to mammals [42]. This system is activated in response to environmental signals, from starvation, disease, and pathogen infection [43]. The targets for degradation are not only proteins, but also organelles and other cellular components. In recent years, the relationship between autophagy and disease has been explored in infections, neurodegenerative diseases, and cancers [44]. In the present study, Ras-associated binding (Rab), ATG, cathepsin, urinary gonadotropin peptide (UGP), (protein kinase D) PKD, and Psen1 were differentially expressed across parasitized and non-parasitized samples, and all have GO terms or KEGG pathways associated with autophagy. During autophagy, the autophagosomes surround the cytosolic components and then fuse with a vacuole, leading to the degradation of the target by lysosomal hydrolases. Autophagy-related (ATG) proteins play a crucial role in the regulation of this process [45]. Prior research showed that the gathering of ATG proteins to form the pre-autophagosomal structure (PAS) is the first step of autophagy $[46,47]$, where 
autophagosomes are normally generated. In mammals, the overexpression of ATG4B was found to make the LC3-PE complex quickly rupture and form the stable complex of LC3, which shows it is a suppressive effector in autophagy [45]. In grouper cells, the transcriptional level of ATG5 was upregulated after infection with Singapore grouper iridovirus (SGIV) and red-spotted grouper nervous necrosis virus (RGNNV). However, the overexpression of ATG5 simultaneously decreased the expression of interferon and negatively regulated the expression of pro-inflammatory factors [48]. ATG9 has been described as a positive regulator that modulates the number of autophagosomes [49]. In a previous study on the Chinese mitten crab, the transcriptional levels of $\operatorname{Atg} 12, \operatorname{Atg} 13$, and $\operatorname{Atg} 16 \mathrm{~L}$ were upregulated in crabs with hepatopancreatic necrosis disease [41]. These results indicate that the upregulation of ATG family members has a positive effect on the immune response in different species. On the contrary, all ATG4 (0.78-fold), ATG5 (0.54-fold), and ATG9 (0.66-fold) proteins were significantly downregulated in crabs with $P$. gregaria infection in the present study. This suggests that autophagy is suppressed in the Chinese mitten crab infected by $P$. gregaria, and that the expression of ATG proteins is involved in this biology process, as part of the host innate immune response. Taken together, this indicates that ATG may play a suppressive role of autophagosomes generation in the autophagy process response to $P$. gregaria infection through diverse mechanisms in the Chinese mitten crab. These mechanisms can differ across species from different pathogens, such as the ATG family, performing differential regulations of the formation of autophagosomes and, therefore, of the autophagy process. One link that is likely very important to this process is the recognition of exogenous ligands. The scavenger receptor (SR), one of the sub-families of pattern recognition receptors (PRRs), recognizes the modified lipoproteins and danger-associated molecular patterns (DAMPs) [50]. One study showed that an increase in the expression of SRs induced by Vibrio parahaemolyticus, lipopolysaccharide (LPS), and white spot syndrome virus (WSSV) efficiently enhanced host phagocytosis to clearance bacteria [51]. Here, we found that SR protein was significantly decreased in response to $P$. gregaria infection in the Chinese mitten crab, likely relating its role in phagocytosis as well as the innate immune system. Interestingly, this pattern is the opposite of what was previously found in a study on Spiroplasma eriocheiris infection in the Chinese mitten crab [52]. This promotes our understanding of $P$. gregaria, whose infection probably silences the innate immune system through inhibition of cell recognition and autophagosome generation on the autophagy process, depending on several modulators (i.e., ATG and SR) in the Chinese mitten crab.

Lysosomes are acidic and hydrolytic organelles responsible for generating targets during endocytosis, phagocytosis, and autophagy [53]. Lysosomes receive or degrade their substrates via various pathways, including endocytosis, phagocytosis, autophagy, lysosomal proteins, soluble lysosomal hydrolases, and others [54]. Lysosome mobilization is a crucial process for phagocyte migration and bactericidal function, although the molecular mechanisms linking these processes remain unclear. Moreover, lysosomes and related organelles travel over long distances along microtubules within the cell cytoplasm during phagocytosis [55]. For lysosomes and endosomes, the active site is mostly a cysteine thiol or an aspartic acid, which functions as the key catalytic site. Some serine proteases, such as cathepsin, granzymes, and a thymus specific serine protease (TSSP), play important roles in the immune system [56]. In this study, 23 DEPs had lysosome-related lysosome GO terms and/or KEGG pathways. These included cathepsin, lysosomal alpha-glucosidase, hexosaminidase, CD63 antigen, and $\beta$-mannosidase. The best known lysosomes and cathepsins are involved in a number of important biological processes, such as intracellular protein turnover, immune response, hormone activation, remodeling of extracellular matrix (ECM), and apoptosis $[57,58]$. In invertebrates, the signaling pathways of MAPK and Imd are the primary components of the innate immune system, and the MAPK pathway has been shown to mediate cathepsin expression induced by all types of cells $[59,60]$. Moreover, JNK, ERK, p38, and Relish are regulators in these signaling pathways [61,62]. In the Chinese mitten crab, previous research has found that all of the expression key factors were decreased when cathepsin D was silenced [63]. Furthermore, using RNAi silenced 
cathepsin $D$ expression caused an obvious decrease in crab immunity and resulted in a significant increase in the mortality of crabs [63]. In mice, the null expression of cathepsin D led to death shortly after birth [64]. Similarly, the expression of cathepsin L was found to distinctly increase following V. anguillarum infection in the Chinese mitten crab [65]. In addition, the over-expression of cathepsin $\mathrm{L}$ was homoplastically induced in black tiger shrimp (Penaeus monodon) [66] and Pacific white shrimp (Litopenaeus vannamei) [67] by lipopolysaccharide and WSSV infection, respectively. On the other hand, in this study, we found that both cathepsin D (0.68-fold) and L (0.65-fold) were dramatically inhibited in parasitized crabs, which suggests that both cathepsin $\mathrm{D}$ and $\mathrm{L}$ perform a crucial role in innate immune function in the Chinese mitten crab. Another cathepsin family member, cathepsin F, was detected as an upregulated (1.40-fold) motif in our study. This protein likely has a similar role to cathepsin S, which cleaves Ii to cross-linking and immunoprecipitation (CLIP) during major histocompatibility complex II (MHC II) Ag processing and presentation [68]. While in crabs, further analysis is needed for this protein function in lysosome-related biology.

The activities of cathepsin, such as cystatins, stefins, tyropins, and serpins, are endogenous protein inhibitors and they tightly bind their target enzymes to prevent substrate hydrolysis [69]. Within the proteinase inhibitor superfamily, serpins are the largest and most diverse family of protease inhibitors [70], and play important roles in many immune processes, such as blood coagulation, complement activation, melanization, and phagocytosis [71]. In recent years, research on serpins in invertebrate indicated that serpins regulate the prophenoloxidase (proPO) activity in Drosophila [72], Penaeus monodon [73], and the Chinese mitten crab [74]. In invertebrates, serpins appear to be unique components of the innate immune response, and are regulated by prophenoloxidase activating enzymes (PPAEs), proteinase inhibitors, lipopolysaccharide, LGBP, and hemolin [75]. A prior study of a Chinese mitten crab infected with Vibrio anguillarum and Pichia pastoris showed that serpins were upregulated, which could be related to serine proteinase involvement in wound healing, proPO activation, phagocytosis, and other defense responses after bacterial and fungal challenges. In Hyphantria cunea, the recombinant serpin and the serine protease inhibitor aprotinin were used to investigate the relationship between serpin and PO activity, the results of which showed that the aprotinin has a stronger inhibitory activity than the recombinant protein at the same concentration, and that the increased serpin expression inhibited PO activity through competition with proPO against the target protease (PPAE) [76] In the present study, we found a different expression pattern, in which serpin expression was significantly decreased (0.49-fold) after P. gregaria infection, which could affect the proPO system of the innate immune response in the Chinese mitten crab. It should be noted that the decrease in serpin expression does not indicate a positive effect on the proPO of the innate immune system, but the abnormal alteration showed an important role in the innate immune response to $P$. gregaria infection. In other words, it is possible that the differential expression of serpin mediates the autophagy process, together with ATG proteins, through the MAPK and/or IMD signaling pathways, also involved in the lysosome and autophagy-animal pathways, serving a direct role in the innate immune response to P. gregaria infection in the Chinese mitten crab.

Biology processes are inarguably complicated, polytropic, and are involved in several molecular factors. Interestingly in the present study, most DEPs relating the innate immune response were downregulated after $P$. gregaria infection, which suggests that $P$. gregaria may induce a suppressive effect on the Chinese mitten crab's innate immune system during infection. As a hypothesis, on the one hand, this consequence may result from the longterm parasitizing [22] of P. gregaria and the newborn cyprid growing in the Chinese mitten crab. On the other hand, this may be due to the co-evolution of the host and parasite, which has resulted in reductions in resistance over time [77]. It is easily understood that the lifestyle of $P$. gregaria continually grows for several months [27,30], from development of the external parts to wither off, upon which, the adults release several broods of larvae [78] during parasitization. It is likely difficult to clean or kill the parasites by themselves of the 
host, which is beneficial for long-term parasitizing and circumventing the crab's attention of the innate immune system [22]. Here, we identified many proteins, domains, GO terms, and KEGG pathways, which were significantly changed in response to $P$. gregaria infection in the Chinese mitten crab at the protein level, and screened for the crucial component relations to the innate immune system, such as ATG, cathepsin, serpins, lysosome- and autophagy-related GO terms, and KEGG pathways. Further study was performed to discuss the mechanisms of ATG, cathepsin, and serpins, which showed a response to $P$. gregaria infection through the autophagy process, with lysosomes participation in the innate immune response in the Chinese mitten crab. Other proteins, such as the Rab family [79], GTPase KRas [80], lectin [81], CD63 [82], and C1QBP [83] were also identified, which were shown to have immune functions in many organisms, and were significantly differentially expressed after $P$. gregaria infection. In this area, to better disentangle these complex signals, more research is needed on the immune response to macroparasites in crabs.

\section{Conclusions}

P. gregaria is a specialized crustacean parasite and draws more attention in recent years. Up to date, few researches were reported for the interactions between this parasite and its host, especially in Chinese mitten crab. Thereby, we first used TMT method to research the innate immune response against $P$. gregaria infection in Chinese mitten crabs. In the present study, many DEPs were identified after P. gregaria infection, and protein domain, subcellular location and Go enrichment were used to analyze protein functions. Moreover, the KEGG pathways were also analyzed to research the mechanisms responding P. gregaria infection in Chinese mitten crab. Finally, we identified DEPs such as Atgs, cathepsins, serpins, GTPase KRas, and lectin, which were mostly enriched in autophagosome assembly, innate immune response GO terms and lysosome, autophagy animal pathways to against the parasite infection through Autophagy process. The innate immune system of Chinese mitten crab was silenced after long-term parasitizing of P. gregaria. These results provided a novel understanding of the innate immune response against $P$. gregaria infection in crabs, as well as other crustaceans. Simultaneously, provided a basis to research the innate immune response of Chinese mitten crab and prevent the parasite infection in aquaculture industry.

Supplementary Materials: The following are available online at https: / www.mdpi.com/article/ 10.3390 / fishes6040057/s1, Figure S1: The quality control by SDS-PAGE. Figure S2: The molecular weight distribution for identified proteins. Figure S3: The heatmapimage analysis between parasitized and non-parasitized crabs. Table S1: The concentration of proteins detected in Chinese mitten crab hepatopancreas. Table S2: Significant enrichment of GO terms $(p<0.05)$ in Chinese mitten crab infected with P. gregaria.

Author Contributions: Conceptualization, Y.Y., K.L. and F.Z.; methodology, Y.Y., F.M., Y.Z., K.L. and F.Z.; software, Y.Y. and P.R.; validation, K.L. and F.Z.; formal analysis, Y.Y.; investigation, Y.Y., J.D., L.L. and P.R.; resources, Y.Y., F.M., J.D., L.L. and Y.W. (Yatao Wu); data curation, Y.Y., F.M. and Y.Z.; writing - original draft preparation, Y.Y.; writing—review and editing, Y.Y.; visualization, Y.Y.; supervision, K.L. and F.Z.; project administration, Y.Y., Y.W. (Yinping Wang), K.L.; funding acquisition, K.L. All authors have read and agreed to the published version of the manuscript.

Funding: This research was funded by the National Key R\&D Program of China (2019YFD0901203); investigation of fishery resources and environment in the lower Yangtze River, the Ministry of Agriculture and Rural Affairs of China (CJDC-2017-22); investigation of fishery resources of the Yangtze Estuary, Special Financial Funds of Shanghai Government (JC202004).

Institutional Review Board Statement: The study was conducted according to the guidelines of the Declaration of Helsinki, and approved by the Institutional Review Board (or Ethics Committee) of Animal Care and Use Committee of the Freshwater Fisheries Research Center at the Chinese Academy of Fishery Sciences. The analysis was carried out following the Guidelines for the Care and Use of Laboratory Animals set by the Animal Care and Use Committee of the Freshwater Fisheries Research Center (2003WXEP61). All operations were carried out with field permit no. 20181AC1128.

Conflicts of Interest: The authors declare no conflict of interest. 


\section{References}

1. Wang, M.; Ge, J.; Yu, J.; Su, S.; Li, J.; Tang, Y. Molecular insights into information processing and developmental and immune regulation of Eriocheir sinensis megalopa under hyposaline stress. Genomics 2020, 112, 4647-4656. [CrossRef] [PubMed]

2. Gillard, M.; Thiébaut, G.; Deleu, C.; Leroy, B. Present and future distribution of three aquatic plants taxa across the world: Decrease in native and increase in invasive ranges. Biol. Invasions 2017, 19, 2159-2170. [CrossRef]

3. Qiu, G.; Xiong, L.; Liu, Z.; Yan, Y.; Shen, H. A first generation microsatellite-based linkage map of the Chinese mitten crab Eriocheir sinensis and its application in quantitative trait loci (QTL) detection. Aquaculture 2016, 451, 223-231. [CrossRef]

4. Bonami, J.; Zhang, S. Viral diseases in commercially exploited crabs: A review. J. Invertebr. Pathol. 2011, 106, 6-17. [CrossRef]

5. Miroliubov, A.; Borisenko, I.; Nesterenko, M.; Korn, O.; Lianguzova, A.; Ilyutkin, S.; Lapshin, N.; Dobrovolskij, A.A. Muscular system in the interna of Polyascus polygenea and Sacculina pilosella (Cirripedia: Rhizocephala: Sacculinidae). Invertebr. Zool. 2019, 16, 48-56. [CrossRef]

6. Yuan, Q.; Wang, Q.; Zhang, T.; Li, Z.; Liu, J. Effects of water temperature on growth, feeding and molting of juvenile Chinese mitten crab Eriocheir sinensis. Aquaculture 2017, 468, 169-174. [CrossRef]

7. Veillet, A. Recherches Sur le Parasitisme des Crabes et des Galathées par les Khizocéphales et les Épicarides; Annales de l'Institut Oceanographique Monaco: Monte-Carlo, Monaco, 1945; Volume 22, pp. 193-341.

8. Wang, J.; Yang, B.; Wang, W.; Song, X.; Jiang, Q.; Qiu, L.; Wang, L.; Song, L. The enhanced immune protection in Chinese mitten crab Eriocheir sinensis against the second exposure to bacteria Aeromonas hydrophila. Front. Immunol. 2019, 10, 2041. [CrossRef] [PubMed]

9. Jiang, H.; Bao, J.; Xing, Y.; Feng, C.; Li, X.; Chen, Q. Proteomic analysis of the hemolymph after Metschnikowia bicuspidata infection in the Chinese mitten crab Eriocheir sinensis. Front. Immunol. 2021, 12, 659-723.

10. Wang, W.; Chen, J. Ultrastructural study on a novel microsporidian, Endoreticulatus eriocheir sp. nov. (Microsporidia, Encephalitozoonidae), parasite of Chinese mitten crab, Eriocheir sinensis (Crustacea, Decapoda). J. Invertebr. Pathol. 2007, 94, 77-83. [CrossRef]

11. Wang, Z.; Wang, L.; Zhou, J.; Zou, J.; Fan, L. New insights into the immune regulation and tissue repair of Litopenaeus vannamei during temperature fluctuation using TMT-based proteomics. Fish Shellfish Immunol. 2020, 106, 975-981. [CrossRef]

12. Sousa, L.G.; Cuartas, E.I.; Petriella, A.M. Fine structural analysis of the epithelial cells in the hepatopancreas of Palaemonetes argentinus (Crustacea, Decapoda, Caridea) in intermoult. Biocell 2005, 29, 25. [CrossRef]

13. Gao, T.; Xu, Y.; Wang, K.; Deng, Y.; Yang, Y.; Lu, Q.; Pan, J.; Xu, Z. Comparative LC-MS based non-targeted metabolite profiling of the Chinese mitten crab Eriocheir sinensis suffering from hepatopancreatic necrosis disease (HPND). Aquaculture 2018, 491, 338-345. [CrossRef]

14. Li, X.; Cui, Z.; Liu, Y.; Song, C.; Shi, G. Transcriptome analysis and discovery of genes involved in immune pathways from hepatopancreas of microbial challenged mitten crab Eriocheir sinensis. PLoS ONE 2013, 8, e68233. [CrossRef]

15. Li, S.; Jia, Z.; Li, X.; Geng, X.; Sun, J. Calmodulin is a stress and immune response gene in Chinese mitten crab Eriocheir sinensis. Fish Shellfish Immunol. 2014, 40, 120-128. [CrossRef] [PubMed]

16. Roux, M.; Pain, A.; Klimpel, K.; Dhar, A. The lipopolysaccharide and $\beta$-1, 3-glucan binding protein gene is upregulated in white spot virus-infected shrimp (Penaeus stylirostris). J. Virol. 2002, 76, 7140-7149. [CrossRef]

17. Ried, C.; Wahl, C.; Miethke, T.; Wellnhofer, G.; Landgraf, C.; Schneider-Mergener, J.; Adolf, H. High affinity endotoxin-binding and neutralizing peptides based on the crystal structure of recombinant Limulus anti-lipopolysaccharide factor. J. Biol. Chem. 1996, 271, 28120-28127. [CrossRef] [PubMed]

18. Gross, P.; Bartlett, T.; Browdy, C.; Chapman, R.; Warr, G. Immune gene discovery by expressed sequence tag analysis of hemocytes and hepatopancreas in the Pacific White Shrimp, Litopenaeus vannamei, and the Atlantic White Shrimp, L. setiferus. Dev. Comp. Immunol. 2001, 25, 565-577. [CrossRef]

19. Glenner, H.; Lützen, J.; Takahashi, T. Molecular and morphological evidence for a monophyletic clade of asexually reproducing Rhizocephala: Polyascus, new genus (Cirripedia). J. Crustacean Biol. 2003, 23, 548-557. [CrossRef]

20. Jorgen, L.; Tohru, T. Sacculina polygenea, a new species of rhizocephalan (Cirripedia: Rhizocephala) from Japan, parasitic on the intertidal crab Hemigrapsus sanguineus (De Haan, 1835) (Decapoda: Brachyura: Grapsidae). Crustacean Res. 1997, $26,103-108$.

21. Høeg, J.; Lützen, J. Crustacea Rhizocephala; Christiansen, M.E., Ed.; Norwegian University Press: Oslo, Norway, 1985; Volume 6, pp. 1-92.

22. Rowley, A.; Davies, C.; Malkin, S.; Bryan, C.; Thomas, J.; Batista, F.; Coates, C. Prevalence and histopathology of the parasitic barnacle, Sacculina carcini in shore crabs, Carcinus maenas. J. Invertebr. Pathol. 2020, 171, 107338. [CrossRef] [PubMed]

23. Hsiao, C.; Wu, Y.; Tung, T.; Wang, G.; Toullec, J.; Liu, S.; Huang, W.; Lee, C. Metabolic effects of parasitisation by the barnacle Polyascus plana (Cirripedia: Rhizocephala: Sacculinidae) on a grapsid host, Metopograpsus thukuhar. Dis. Aquat. Org. 2016, 119, 199-206. [CrossRef]

24. Waiho, K.; Fazhan, H.; Glenner, H.; Ikhwanuddin, M. Infestation of parasitic rhizocephalan barnacles Sacculina beauforti (Cirripedia, Rhizocephala) in edible mud crab Scylla Olivacea. Peer] 2017, 5, e3419. [CrossRef]

25. Tsuchida, K.; Lützen, J.; Nishida, M. Sympatric three-species infection by Sacculina parasites (Cirripedia: Rhizocephala: Sacculinidae) of an intertidal grapsoid crab. J. Crustacean Biol. 2006, 26, 474-479. [CrossRef]

26. Mouritsen, K.N.; Jensen, T. The effect of Sacculina carcini infections on the fouling, burying behaviour and condition of the shore crab, Carcinus maenas. Ophelia 2006, 2, 270-275. 
27. Heg, J.T. The biology and life cycle of the Rhizocephala (Cirripedia). J. Mar. Biol. Assoc. 1995, 75, 517-550. [CrossRef]

28. Kristensen, T.; Nielsen, A.; Jørgensen, A.; Mouritsen, K.; Glenner, H.; Christensen, J.; Lützen, J.; Høeg, J. The selective advantage of host feminization: A case study of the green crab Carcinus maenas and the parasitic barnacle Sacculina carcini. Mar. Biol. 2012, 159, 2015-2023. [CrossRef]

29. Adam, P.; Rowley, A.F. Tissue changes in the shore crab Carcinus maenas as a result of infection by the parasitic barnacle Sacculina carcini. Dis. Aquat. Org. 2008, 80, 75-79.

30. Lützen, J. Growth, reproduction, and life span in Sacculina carcini Thompson (Cirripedia: Rhizocephala) in the Isefjord, Denmark. Sarsia 1984, 69, 91-105. [CrossRef]

31. Trédez, F.; Rabet, N.; Bellec, L.; Audebert, F. Synchronism of naupliar development of Sacculina carcini Thompson, 1836 (Pancrustacea, Rhizocephala) revealed by precise monitoring. Helgol. Mar. Res. 2016, 70, 26. [CrossRef]

32. Waiho, K.; Fazhan, H.; Zhang, Y.; Afiqah-Aleng, N.; Moh, J.; Ikhwanuddin, M.; Hassan, M.; Norainy, M.; Ma, H. Gonadal transcriptomic analysis of the mud crab Scylla olivacea infected with rhizocephalan parasite Sacculina beauforti. Genomics 2020, 112, 2959-2969. [CrossRef]

33. Tang, B.; Wang, Q.; Chen, L.; Yang, S. Features of an intersex Chinese mitten crab, Eriocheir Japonica sinensis (decapoda, brachyura). Freshw. Fish 2005, 78, 371-377. [CrossRef]

34. Yamaguchi, T.; Aratake, H. Morphological modifications caused by Sacculina polygenea in Hemigrapsus sanguineus (De Haan) (Brachyura: Grapsidae). Crustacean Res. 1997, 26, 125-145. [CrossRef]

35. Iwanaga, S.; Lee, B.-L. Recent advances in the innate immunity of invertebrate animals. BMB Rep. 2005, 38, 128-150. [CrossRef]

36. Jiravanichpaisal, P.; Lee, B.L.; Söderhäll, K. Cell-mediated immunity in arthropods: Hematopoiesis, coagulation, melanization and opsonization. Immunobiology 2006, 211, 213-236. [CrossRef]

37. Kong, P.; Wang, L.; Zhang, H.; Zhou, Z.; Qiu, L.; Gai, Y.; Song, L. Two novel secreted ferritins involved in immune defense of Chinese mitten crab Eriocheir sinensis. Fish Shellfish Immunol. 2010, 28, 604-612. [CrossRef]

38. Chen, Y.; Huang, A.; Ao, W.; Wang, Z.; Yuan, J.; Song, Q.; Wei, D.; Ye, H. Proteomic analysis of serum proteins from HIV / AIDS patients with Talaromyces marneffei infection by TMT labeling-based quantitative proteomics. Clin. Proteom. 2018, 15, 40. [CrossRef]

39. Wu, J.; Wang, Y.; Jiang, Z. Immune induction identified by TMT proteomics analysis in Fusobacterium nucleatum autoinducer-2 treated macrophages. Expert Rev. Proteom. 2020, 17, 175-185. [CrossRef]

40. Du, N.S. Crustaceology; Scence Press: Beijing, China, 1987; Volume 1.

41. Yan, B.; Liu, X.; Zhou, Y.; Zhang, M.; Fang, P.; Jiang, M.; Yuan, R.; Hu, X.; Gao, G.; Xue, R.; et al. Transcriptomic analysis reveals that hepatopancreatic necrosis disease in Eriocheir sinensis (Chinese mitten crabs) may be the result of autophagy and apoptosis. Aquaculture 2020, 515, 734579. [CrossRef]

42. Mizushima, N.; Komatsu, M. Autophagy: Renovation of cells and tissues. Cell 2011, 147, 728-741. [CrossRef]

43. Sun, M.X.; Huang, L.; Wang, R.; Yu, Y.L.; Li, C.; Li, P.P.; Hu, X.C.; Hao, H.P.; Ishag, H.A.; Mao, X. Porcine reproductive and respiratory syndrome virus induces autophagy to promote virus replication. Autophagy 2012, 8, 1434-1447. [CrossRef]

44. Galluzzi, L.; Pedro, J.; Levine, B.; Green, D.; Kroemer, G. Pharmacological modulation of autophagy: Therapeutic potential and persisting obstacles. Nat. Rev. Drug Discov. 2017, 16, 487-511. [CrossRef]

45. Maruyama, T.; Noda, N.N. Autophagy-regulating protease Atg4: Structure, function, regulation and inhibition. J. Antibiot. 2018, 71, 72-78. [CrossRef]

46. Suzuki, K.; Kirisako, T.; Kamada, Y.; Mizushima, N.; Noda, T.; Ohsumi, Y. The pre-autophagosomal structure organized by concerted functions of APG genes is essential for autophagosome formation. EMBO J. 2001, 20, 5971-5981. [CrossRef]

47. Suzuki, K.; Kubota, Y.; Sekito, T.; Ohsumi, Y. Hierarchy of Atg proteins in pre-autophagosomal structure organization. Clarendon Press 2007, 12, 209-218. [CrossRef] [PubMed]

48. Li, C.; Liu, J.; Zhang, X.; Wei, S.; Huang, X.; Huang, Y.; Wei, J.; Qin, Q. Fish Autophagy Protein 5 Exerts Negative Regulation on Antiviral Immune Response against Iridovirus and Nodavirus. Front. Immunol. 2019, 10, 517. [CrossRef]

49. Jin, M.; Klionsky, D.J. Transcriptional regulation of ATG9 by the Pho23-Rpd3 complex modulates the frequency of autophagosome formation. Autophagy 2014, 10, 1681-1682. [CrossRef] [PubMed]

50. Canton, J.; Neculai, D.; Grinstein, S. Scavenger receptors in homeostasis and immunity. Nat. Rev. Immunol. 2013, 13, 621-634. [CrossRef]

51. Luzio, J.P.; Pryor, P.R.; Bright, N.A. Lysosomes: Fusion and function. Nat. Rev. Mol. Cell Biol. 2007, 8, 622-632. [CrossRef]

52. Hou, L.; Zhou, H.; Wan, H.; Liu, Z.; Wang, L.; Cheng, Y.; Wu, X.; Gu, W.; Wang, W.; Meng, Q. TMT-based quantitative proteomic analysis of Eriocheir sinensis hemocytes and thoracic ganglion during Spiroplasma eriocheiris infection. Fish Shellfish Immunol. 2020, 96, 126-137. [CrossRef]

53. Hipolito, V.E.B.; Ospina-Escobar, E.; Botelho, R.J. Lysosome remodelling and adaptation during phagocyte activation. Cell Microbiol. 2018, 20, e12824. [CrossRef]

54. Raposo, G.; Fevrier, B.; Stoorvogel, W.; Marks, M. Lysosomes related organelles: A view from immunity and pigmentation. Cell Struct. Funct. 2002, 27, 443-456. [CrossRef]

55. Labrousse, A.M.; Meunier, E.; Record, J.; Labernadie, A.; Beduer, A.; Vieu, C.; Safta, T.; Maridonneau-Parini, I. Frustrated phagocytosis on micro-patterned immune complexes to characterize lysosome movements in live macrophages. Front. Immunol. 2011, 2, 51. [CrossRef] 
56. Colbert, J.; Matthews, S.; Miller, G.; Watts, C. Diverse regulatory roles for lysosomal proteases in the immune response. Eur. J. Immunol. 2009, 39, 2955-2965. [CrossRef]

57. Turk, B.; Turk, D.; Turk, V. Lysosomal cysteine proteases: More than scavengers. Biochim. Biophys. Acta 2000, 1477, 98-111. [CrossRef]

58. Turk, B.; Stoka, V.; Rozman-Pungercar, J.; Cirman, T.; Droga-Mazovec, G.; Oreic, K.; Turk, V. Apoptotic Pathways: Involvement of lysosomal proteases. Biol. Chem. 2002, 383, 1035-1044. [CrossRef]

59. Keegan, P.M.; Wilder, C.L.; Platt, M.O. Tumor necrosis factor alpha stimulates cathepsin K and V activity via juxtacrine monocyteendothelial cell signaling and JNK activation. Mol. Cell Biochem. 2012, 367, 65-72. [CrossRef]

60. Tsukuba, T.; Yanagawa, M.; Kadowaki, T.; Takii, R.; Okamoto, Y.; Sakai, E.; Okamoto, K.; Yamaoto, K. Cathepsin E deficiency impairs autophagic proteolysis in macrophages. PLoS ONE 2013, 8, e82415. [CrossRef]

61. Lemaitre, B.; Hoffmann, J. The Host Defense of Drosophila melanogaster. Annu. Rev. Immunol. 2007, 25, 697-743. [CrossRef]

62. Zhang, Y.; Lu, Y.X.; Liu, J.; Yang, C.; Feng, Q.; Xu, W. A regulatory pathway, Ecdysone-transcription factor Relish-Cathepsin L, is involved in insect fat body dissociation. PLoS Genet. 2013, 9, e1003273. [CrossRef]

63. Ning, M.; Yuan, M.; Liu, M.; Gao, Q.; Wei, P.; Gu, W.; Wang, W.; Meng, Q. Characterization of cathepsin D from Eriocheir sinensis involved in Spiroplasma eriocheiris infection. Dev. Comp. Immunol. 2018, 86, 1-8. [CrossRef]

64. Tulone, C.; Uchiyama, Y.; Novelli, M.; Grosvenor, N.; Softig, P.; Chain, B. Haematopoietic development and immunological function in the absence of cathepsin D. BMC Immunol. 2007, 8, 22. [CrossRef]

65. Li, W.; Jin, X.; He, L.; Jiang, H.; Gong, Y.; Xie, Y.; Wang, J. Molecular cloning, characterization, expression and activity analysis of cathepsin L in Chinese mitten crab, Eriocheir sinensis. Fish Shellfish Immunol. 2010, 29, 1010-1018. [CrossRef]

66. Qiu, L.; Jiang, S.; Huang, J.; Wang, W.; Zhang, D.; Wu, Q.; Yang, K. Molecular cloning and mRNA expression of cathepsin C gene in black tiger shrimp (Penaeus monodon). Comp. Biochem. Physiol. Part A Mol. Integr. Physiol. 2008, 150, 320-325. [CrossRef]

67. Zhao, Z.; Yin, Z.; Weng, S.; Guan, H.; Li, S.; Xing, K.; Chan, S.; He, J. Profiling of differentially expressed genes in hepatopancreas of white spot syndrome virus-resistant shrimp (Litopenaeus vannamei) by suppression subtractive hybridisation. Fish Shellfish Immunol. 2007, 22, 520-534. [CrossRef]

68. Shi, G.P.; Bryant, R.A.R.; Riese, R.; Verhelst, S.; Driessen, C.; Li, Z.; Bromme, D.; Ploegh, H.; Chapman, H. Role for Cathepsin F in invariant chain processing and Major Histocompatibility Complex Class II peptide loading by Macrophages. J. Exp. Med. 2000, 191, 1177-1186. [CrossRef]

69. Turk, B.; Turk, D.; Salvesen, G. Regulating cysteine protease activity: Essential role of protease inhibitors as guardians and regulators. Curr. Pharm. Des. 2002, 8, 1623-1637. [CrossRef]

70. Zhao, Y.; Xu, Y.; Jiang, H.; Xu, S.; Zhao, X.; Wang, J. Antibacterial activity of serine protease inhibitor 1 from kuruma shrimp Marsupenaeus japonicus. Dev. Comp. Immunol. 2014, 44, 261-269. [CrossRef]

71. Rimphanitchayakit, V.; Tassanakajon, A. Structure and function of invertebrate Kazal-type serine proteinase inhibitors. Dev. Comp. Immunol. 2009, 34, 377-386. [CrossRef]

72. Tang, H.; Kambris, Z.; Lemaitre, B.; Hashimoto, C. A serpin that regulates immune melanization in the respiratory system of Drosophila. Dev. Cell 2008, 15, 617-626. [CrossRef]

73. Wetsaphan, N.; Rimphanitchayakit, V.; Tassanakajon, A.; Somboonwiwat, K. PmSERPIN3 from black tiger shrimp Penaeus monodon is capable of controlling the proPO system. Dev. Comp. Immunol. 2013, 41, 110-119. [CrossRef]

74. Wang, L.; Ma, Z.; Yang, J.; Gai, Y.; Zhou, Z.; Wang, L.; Yue, F.; Song, L. Identification and characterization of a serine protease inhibitor Esserpin from the Chinese mitten crab Eriocheir sinensis. Fish Shellfish Immunol. 2013, 34, 1576-1586. [CrossRef] [PubMed]

75. Söderhäll, K.; Cerenius, L. Role of the prophenoloxidase-activating system in invertebrate immunity. Curr. Opin. Immunol. 1998, 10, 23-28. [CrossRef]

76. Park, D.; Shin, S.; Hong, S.; Park, H. Immunological detection of Serpin in the Fall webworm, Hyphantria cunea and its inhibitory activity on the prophenoloxidase system. Mol. Cells 2000, 10, 186-192. [CrossRef]

77. Koskella, B. Resistance gained, resistance lost: An explanation for host-parasite coexistence. PLoS Biol. 2018, 16, e3000013. [CrossRef]

78. Jensen, A.; Schneider, M.; Høeg, J.; Glenner, H.; Lützen, J. Variation in juvenile stages and success of male acquisition in Danish and French populations of the parasitic barnacle Sacculina carcini (Cirripedia: Rhizocephala) parasitizing the shore crab Carcinus maenas. Mar. Biol. Res. 2019, 15, 191-203. [CrossRef]

79. Han, F.; Zhang, X. Characterization of a ras-related nuclear protein (Ran protein) up-regulated in shrimp antiviral immunity. Fish Shellfish Immunol. 2007, 23, 937-944. [CrossRef]

80. Scheele, J.S.; Marks, R.E.; Boss, G.R. Signaling by small GTPases in the immune system. Immunol. Rev. 2007, $218,92-101$. [CrossRef]

81. Patin, E.C.; Orr, S.J.; Schaible, U.E. Macrophage Inducible C-Type Lectin as a Multifunctional Player in Immunity. Front. Immunol. 2017, 8, 861. [CrossRef]

82. Liyanage, D.; Omeka, W.; Yang, H.; Lim, C.; Kwon, H.; Choi, C.; Lee, J. Expression profiling, immune functions, and molecular characteristics of the tetraspanin molecule CD63 from Amphiprion clarkii. Dev. Comp. Immunol. 2021, 123, 104168. [CrossRef]

83. Wang, Y.; Su, J.; Yuan, B.; Fu, D.; Niu, Y.; Yue, D. The role of C1QBP in CSF-1-dependent PKC $\zeta$ activation and macrophage migration. Exp. Cell Res. 2018, 362, 11-16. [CrossRef] 